\title{
Comparison of the Histologic Results of Atypical Glandular Cells- Favor Neoplasia and Atypical Glandular Cells-Not Otherwise Specified
}

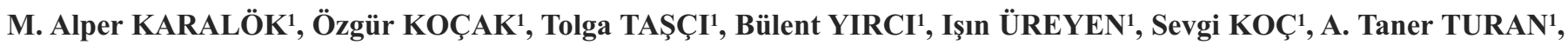 \\ H. Gökhan TULUNAY ${ }^{1}$
}

Ankara, Turkey

\begin{abstract}
OBJECTIVE: Cervical cancer screening programs are widely performed in all around the world. The interpretation of the Pap smear test is a big challenge in gynecology practice particularly when associated with atypical glandular cells. In this study, we performed a retrospective analysis of cytologic results associated with atypical glandular cells in our institution.
\end{abstract}

MATERIAL AND METHOD: We retrospectively reviewed Pap smear tests resulted as "atypical glandular cells". A total of 122 women had screening tests reported as "atypical glandular cells" between 2003 and 2013 at the Ministry of Health, Etlik Maternity and Women's Health Teaching Research. The cytology reported as "atypical glandular cells" were evaluated in two main groups: Atypical glandular cellsfavor neoplasia (AGC-FN) and atypical glandular cells-not otherwise specified (AGC-NOS) compared by means of histologic results.

RESULTS: Thirty-two women have been reported as AGC-NOS on cytologic examination and 90 women were defined as AGC-FN. There was no significant difference between AGC-FN and AGC NOS groups in terms of age. In AGC-FN group, a total of 13 women (13/90) (14.4\%) had malignant histological diagnosis. In AGC-NOS group only one woman (1/32) (3.1\%) was diagnosed as malignant. All the malignant cases in this study are older than 35 years.

CONCLUSION: The incidence of AGC is less than $1 \%$ in all Pap smear examinations. Two main factors were important in the outcome of the AGC. The first one is the subgroup. AGC-FN group has a higher risk of malignancy. The second important factor is the age of the patient. To be older than 35 years old seems to increase the risk of malignancy.

Keywords: Atypical glandular cells favor neoplasia, Atypical glandular cells-not otherwise specified

Gynecol Obstet Reprod Med 2016;22:27-31

\section{Introduction}

Due to the technologic development and development in the cervical screening programs, the incidence of the cervical cancer and the mortality of the cervical cancer decreased significantly. ${ }^{1}$ The premalignant cells can be detected and its progress to invasive cancer can be successfully prevented by means of cytological screening. By cytological screening, premalignant cells can be detected and progress to invasive cancer can be prevented. The early detection of these premalignant cells is crucial since it gives sufficient time before malignant transformation takes place. Cervix is accessible to get exfoliated cells by Pap smear test. Pap smear test is inexpensive

${ }^{I}$ Etlik Maternity and Women's Health Teaching Research Hospital, Department of Maternal Fetal Medicine, Ankara

Address of Correspondence: Özgur Koçak

Etlik Maternity and Women's Health Teaching Research Hospital Department of Maternal Fetal Medicine, Ankara, Turkey dr.ozgur@hotmail.com

Submitted for Publication: 24. 04.2015

Accepted for Publication:

26. 01.2016 and can be easily be done; so it is one of the best screening tests that has ever been investigated.

Most of the cervical cancer cells take origin from squamous cells of the ectocervix. In last few decades, by the help of widely used cervical cancer screening programs, the incidence of the squamous cervical cancer decreased and cervical adenocarcinomas increased relatively particularly in younger women. $^{2-3}$ Percentage of the adenocarcinoma to all cervical cancer increased from 5 to $20-25 .{ }^{4}$ This increase suggests that the screening test is not efficient to detect the premalignant cells of the adenocarcinoma. The clinical importance of detecting premalignant cell in the Pap smear test is to decide about treatment or follow up. Premalignant cells may regress spontaneously. However, some women may require treatment whose Pap smear results denote high grade histological abnormalities or cervical carcinoma. There should be a balance between follow-up and over treatment. Unfortunately early detection of premalignant cells is not possible every time. It is easy to sample the squamous cell of cervix by Pap test. The squamous lesion is also easy to detect on colposcopic examination. The anatomy of the cervix is more suitable to evaluate 
ectocervix. Endocervix evaluation is more difficult by direct examination or colposcopic examination so the interpretation of atypical glandular cells (AGC) which are derived from endocervix is very difficult. As a result, the algorithm of the atypical glandular cell on Pap smear test is a challenge in gynecology. ${ }^{5}$ In addition to malignant situations, approximately $60 \%$ of AGC on Pap test is due to benign conditions. ${ }^{6}$ Endocervicitis, endometriosis, micro glandular hyperplasia, tubal metaplasia, lower uterine segment cells, post conization sampling, radiation effect, thermal injury, endometrial polyp, exogenous hormone effect, pregnancy, endosalpingiosis may cause AGC cytology. For this reason, current guidelines recommend extensive evaluation of the women whose Pap smear test reported as AGC. ${ }^{6-9}$

Bethesda is a kind of system used for cervical and vaginal cytological examinations and used for Pap smear test results reporting. Bethesda system was defined for the first time in 1988 and revised two times in 1991 and 2001. ${ }^{10-13}$ An atypical glandular cell of undetermined significance (formerly AGUS) was changed as AGC to avoid confusion with ASCUS. ${ }^{14}$ The last revision of Bethesda system was done in 2001 and atypical glandular cells was divided in to three categories; AGC not otherwise specified (NOS), AGC favor neoplasia (AGC-FN) and adenocarcinoma in situ (AIS). By these changes in terminology, the number of detected cytological glandular abnormalities increased. ${ }^{15-17}$

Cancer screening program in Turkey continues and cervical cancer screening in 2013 increased 23\% when compared 2012. ${ }^{18}$ The Ministry of Health refers women with high risk HPV DNA (+) results to hospitals for further evaluation and treatment.

The main purpose of this study is to make correlation between cytology and histopathology of AGC-NOS and AGCFN subtypes and give additional information to literature about the refined treatment and follow up algorithm of the AGC.

\section{Material and Method}

In this study, the results of endocervical curettage (ECC), endometrial sampling and cervical biopsies taken under colposcopic examination of 122 sequential women with a diagnosis of AGC on pap-smear in our center between 2003 and 2013 were assessed retrospectively. All smears were done conventionally. The AGC terminology was used according to the Bethesda System (2001). In our study, all the AGC reported smear tests were evaluated retrospectively and two main groups; AGC-FN and AGC-NOS were compared. The main criteria to define atypical cell as AGC-NOS were; (1) loss of orderly architecture with nuclei overlapping and crowding, (2) nuclear enlargement up to 5 times of the size of normal endocervical nuclei (nuclear enlargement: 2 times: reactive), (3) increased nucleus/cytoplasm ratio, (4) presence of nucleoli, (5) mild hyperchromasia, (6) some variations in nuclear size and shape.
For the AGC, the traditional treatment strategy was to refer to colposcopy if any abnormalities detected in the second smear. However, lots of new studies show that one third of the women with AGC smear result have borderline or high grade glandular abnormalities including adenocarcinoma of the cervix or endometrium and other pathologies. ${ }^{19-21}$ These studies changed the management of the AGC in a way that one single glandular abnormality in smear is enough for referring the patient to colposcopy. In our center, every woman with a result of AGC on smear test is referred to colposcopy. All biopsies and endocervical curettages in this study were performed during colposcopic examination. The first evaluation of the women with AGC does not include human papillomavirus (HPV) testing and not recommended until 2007 and HPV testing were not studied for these women. ${ }^{22}$

Statistical analysis was done with SPSS ${ }^{\circledR}$ software package version 21.0 (IBM, Armonk, New York, USA) on Windows 8. Differences in groups associated with different outcomes were evaluated using univariable analysis (cross-tabulation with $\chi^{2}$ test). $\mathrm{p}<0.05$ was considered significant, adjusting for multiple comparisons. For continuous variables descriptive statistics (mean, standard deviation, and median) were calculated. For discrete variables, counts (n) and percentage (\%) were calculated. For independent samples we conducted two-sample ttest of means.

\section{Results}

A total of 122 women with Pap smears reported as AGCFN or AGC-NOS who have histological follow-up were evaluated in this study. First subgroup consisted of 32 women with smears reported as AGC-NOS (not otherwise specified). The second subgroup consisted of 90 women with smears reported as AGC-FN. Each case has been followed up for at least 1 year. The first evaluation of these women includes colposcopic examination and endocervical curettage. Histopathologic evaluation is defined as the secondary evaluation (cervical biopsy, cold knife conization, loop electrosurgical excision procedure).

In the AGC-FN group, there were 90 women with ages ranging from 26-69 and the mean \pm standard deviation of the age was $46.8 \pm 10$ years with a median of 47 years. In AGC NOS group there were 32 women with ages ranging from 25 76 and the mean \pm standard deviation of the group age was 47 \pm 10.9 years with a median of 48 years. There were no significant differences between AGC-FN and AGC NOS groups by means of age $(p=0.940)$.

Number of endometrial biopsy in AGC-FN group was $81 / 90$ (90\%). In the AGC-NOS group, number of endometrial biopsy was 29/31 (91.6\%). The percentage of endometrial biopsies was not statistically different in each group $(\mathrm{P}=$ 0.710). In the AGC-FN group, 5 women were diagnosed as adenocarcinoma by endometrial sampling and there was no adenocarcinoma case in AGC-NOS group ( $\mathrm{p}=0.001)$. This finding was statistically significant. 
ECC was performed in 83/90 (92.2\%) and 29/32 (90.6\%) women AGC-FN and AGC-NOS groups, respectively and there was no statistical difference between two groups ( $\mathrm{p}=$ 0.604). In AGC-FN group, 2 women were diagnosed as adenocancer by ECC. In addition, ECC was reported as endometrial hyperplasia and adenocancer could not be excluded in one woman. For this case, endometrial biopsy was performed at the same time and was reported as atypical glandular hyperplasia. This woman was 62 years old and total abdominal hysterectomy and bilateral salpingo-oophorectomy was performed and final pathology was reported as stage I endometrioid adenocancer of endometrium. In AGC group, 2 women had ECCs reported as endometrial hyperplasia and endometrial samplings of these women were normal. The final diagnosis of both women was normal and no pathology was detected during 1 year follow up.
Number of cervical biopsies in AGC-FN group were 54/90 $(60 \%)$ and $22 / 32(68.7 \%)$ in AGC-NOS group ( $p=0.648)$. Adenocarcinoma was reported via cervical biopsies in 3 women in AGC-FN group and no adenocarcinoma cases were detected in AGC-NOS group.

In this study, 16 women are younger than 35 years. Eleven women were in AGC-FN group and 5 women were in AGCNOS group. In the subgroup analysis of women less than 35 years, only 2 women had HGSIL in AGC-FN group. There was no HGSIL in AGC-NOS group. In this age group no malignant case was observed. All the malignant cases in this study are older than 35 years. The detailed information about groups was shown in Table 1.

Table 1: Characteristics of women with AGC-FN and AGC-NOS

\begin{tabular}{|c|c|c|}
\hline Cytologic Result & ACG-FN (n:90) & AGC - NOS (n:32) \\
\hline Age & 26-69 (Mean:46.8) & 25-76 (Mean: 47) \\
\hline Number of endometrial biopsy & $81(90 \%)$ & $29(91,6 \%)$ \\
\hline Adeno CA & $5(5.6 \%)$ & - \\
\hline Endometrial Hiperplasia & $3(3.3 \%)$ & $1(3.1 \%)$ \\
\hline Atypic Epithelial Cells & $1(1.1 \%)$ & - \\
\hline Serous carsinom & $1(1.1 \%)$ & $1(3.1 \%)$ \\
\hline Normal & $71(78,9 \%)$ & $27(84,4 \%)$ \\
\hline Number of Endocervical curettage & $90(100 \%)$ & $32(100 \%)$ \\
\hline Adeno CA & $2(2.2 \%)$ & - \\
\hline End hiperplazi/ Adeno Ca not Excluded & $1(1.1 \%)$ & $2(6.3 \%)$ \\
\hline Carsinom & - & $1(3.1 \%)$ \\
\hline \multicolumn{3}{|l|}{ Endometrial Hiperplazi } \\
\hline HSIL & $4(4.4 \%)$ & - \\
\hline CIN /LSIL & $1(1.1 \%)$ & - \\
\hline Normal & $83(92.2 \%)$ & $29(90,6 \%)$ \\
\hline Number of Cervical biopsy & $54(60 \%)$ & $22(68,7 \%)$ \\
\hline Adeno CA & $3(3.3 \%)$ & \\
\hline LSIL/SIL & $4(4.4 \%)$ & $1(3,1 \%)$ \\
\hline HSIL/ & $5(5.5 \%)$ & $1(3.1 \%)$ \\
\hline Chronic Cervisitis & & $2(6.3 \%)$ \\
\hline Normal & $42(46.7 \%)$ & $18(56,3 \%)$ \\
\hline Number of Second Cervical biopsy & $49(54,4 \%)$ & $14(43,7 \%)$ \\
\hline Adeno CA & $2(2.2 \%)$ & $1(3,1 \%)$ \\
\hline \multicolumn{3}{|l|}{ Atypical Cells can not Exclude Adeno CA } \\
\hline AGC & $1(1.1 \%)$ & \\
\hline LSIL/SIL & $4(4.4 \%)$ & \\
\hline HSIL/CIN2 & $3(3.3 \%)$ & $1(3.1 \%)$ \\
\hline Normal & $39(43.3 \%)$ & $12(37,5 \%)$ \\
\hline Total of squamous neoplasia & $1(1.1 \%)$ & \\
\hline Total of glandular neoplasia & $12(13.3 \%)$ & $1(3.1 \%)$ \\
\hline Total Number of cases & 90 & 32 \\
\hline
\end{tabular}

AGC: Atypical glandular cells, NOS: Not otherwise specification, HSIL: High-grade squamous intraepithelial lesion, AIS: Adenocarcinoma in situ, CIN: Cervical intraepithelial neoplasia 


\section{Discussion}

The incidence of AGC is less than $1 \%$ in all Pap smear examination. The rate of diagnosis of AGC depends on so many factors such as pathologist's expert, population, the smear technique. So there is a wide difference in the diagnosis of AGC. It may be reported as low as $0.05 \%$ to as much as $0.4 \% .^{23,24}$ Because our hospital is a reference center in our country, we couldn't give the population-based rate of the diagnosis of AGC. As mentioned before, all women in this study were followed-up at least 1 year. The interobserver variability is quite high in the diagnosis of AGC. In one study, the reported sensitivity is $63 \%$ and specificity is $58 \%{ }^{25}$ By followup we found important cellular abnormities in approximately one third of women with AGC. The detection rate of clinically significant lesions was increased when the women's histopathologies were reported as AGC-FN. Liquid based cytology is more efficient to show glandular cells on cytology. ${ }^{26}$ According to current American Society for Colposcopy and Cervical pathology guideline; initial workup of women with AGC is colposcopy and endocervical sampling. If a woman is older than 35 years or at risk of endometrial neoplasia, endometrial sampling should be added. ${ }^{27}$ The role of HPV testing is not well understood. In a study, it was reported that women with HPV positivity were 12 times more likely to have cervical intraepithelial neoplasia compared to HPV negative women with AGC. ${ }^{28}$

In conclusion, two main factors play a role in the outcome of the AGC in our study. The first one is the subgroup. The malignancies were observed in $14(11.5 \%)$ women with AGC. A total of 13 women diagnosed as malignant were in AGC-FN group, only 1 woman was in AGC-NOS group. Scheiden et al reported malignancy rate as $\% 10$ with AGC in conventional cervical smear. ${ }^{29}$ This malignancy rate is similar with our our finding which is $11.5 \%$. The second important factor is the age of the women. All the clinically significant lesions were detected in women older than 35 years. In fact, our study is in line with the recommendation issued by the ASCCP in 2013. ${ }^{27}$

\section{References}

1. Laara E, Day NE, Hakama M. Trends in mortality from cervical cancer in the Nordic countries: association with organised screening programmes. Lancet 1987;1:1247-9.

2. Gien LT, Beauchemin MC, Thomas G. Adenocarcinoma: a unique cervical cancer. Gynecol Oncol 2010;116:140-6.

3. Wang SS, Sherman ME, Hildesheim A, et al. Cervical adenocarcinoma and squamous cell carcinoma incidence trends among white women and black women in the United States for 1976-2000. Cancer 2004;100:1035-44

4. Smith HO, Tiffany MF, Qualls CR, et al. The rising incidence of adenocarcinoma relative to squamous cell carcinoma of the uterine cervix in the United States-a 24-year populationbased study. Gynecol Oncol 2000;78:97-105.
5. Kinney W, Sawaya G, Sung H, et al. Stage at diagnosis and mortality in patients with adenocarcinoma and adenosquamous carcinoma of the cervix diagnosed as a consequence of cytologic screening. Acta Cytol 2003; 47:167-71.

6. Van DT, Haque M, Lucci JA III, et al. Management of atypical glandular cells of undetermined significance pap smears: a reappraisal. J Low Genit Tract Dis 2003;7:11-5.

7. Schorge JO, Rauh-Hain JA. Atypical glandular cells. Clini cal Obstet Gynecol 2013;56:35-43

8. Wright TC Jr, Massad LS, Dunton CJ, Spitzer M, Wilkinson EJ, Solomon D. 2006 consensus guidelines for the management of women with abnormal cervical screening tests. J Low Genit Tract Dis 2007;11:201-2.

9. Dunton CJ. Management of atypical glandular cells and adenocarcinoma in situ. Obstet Gynecol Clin North Am 2008;35:623-32.

10. The 1988 Bethesda System for reporting cerval/vaginal cytologic diagnoses: developed and approved at the National Cancer Institute workshop in Bethesda, MD, December 12-13,1988. Diagn Cytopathol 1989;5(3):331-4.

11. Broder S. The Bethesda System for Reporting Cervical/ Vaginal Cytologic Diagnoses-Report of the 1991 Bethesda Workshop. Cancer 1992;69:3020

12. Nayar R, Solomon D. Second edition of "The Bethesda System for reporting cervical cytology" - Atlas, website, and Bethesda interobserver reproducibility project. Cyto Journal 2004;1:4

13. Solomon D, Davey D, Kurman R, et al. The 2001 Bethesda System: terminology for reporting results of cervical cytology. JAMA 2002;287(16):2114-19

14. Apgar BS, Zoschnick L, Wright TC. The 2001 Bethesda System terminology. Am Fam Physician 2003;68(10): 1992-8.

15. Wright Jr TC, Cox JT, Massad LS, Twiggs LB, Wilkinson EJ. ASCCP Sponsored Consensus Conference. 2001 Consensus Guidelines for the management of women with cervical cytological abnormalities. JAMA 2002;287(16): 2120-9.

16. Covell JL, Wilbur DC, Guidos B, Lee KR, Chhieng DC, Mody DR. Epithelial abnormalities: glandular. In: Solomon D, Nayar R, editors. The Bethesda System for reporting cervical cytology: definitions, criteria and explanatory notes. New York: Springer-Verlag 2004;123-56.

17. Daniel A, Barreth D, Schepansky A, Johnson G, Capstick V, Faught W. Histologic and clinical significance of atypical glandular cells on pap smears. Int J Gynaecol Obstet 2005;91(3):238-42

18. Kanser İstatistikleri 2013 Hastalık ve Tedavi (cited 2015 Aug 15); Available from: URL: http://kanser.gov.tr/ kanser/kanser-taramalari/915-2013-kanser-tarama-istatistikleri.html 
19. Ronnett BM, Manos MM, Ransley JE. et al. Atypical glandular cells of undetermined significance (AGUS):cytopathologic features, histopathologic results, and humanpapillomavirus DNA detection. Hum Pathol 1999;30:81625.

20. Cullimore J, Scurr J. The abnormal glandular smear: cytologic prediction, colposcopic correlation and clinical management. J Obstet Gynaecol 2000;20:403-7.

21. Patel A, Thampy N, Hemming D, Naik R. A clinical review of borderline glandular cells reported on liquidbased cervical cytology. BJOG 2010;117:1051-9.

22. Wright TC Jr, Massad LS, Dunton CJ, Spitzer M, Wilkinson EJ, Solomon D. 2006 consensus guidelines for the management of women with abnormal cervical screening tests. J Low Genit Tract Dis 2007;11:201-222.

23. Davey DD, Neal MH, Wilbur DC et al. Bethesda 2001 implementation and reporting rates: 2003 practices of participants in the College of American Pathologists Interlaboratory Comparison Program in Cervicovaginal Cytology. Arch Pathol Lab Med 2004;128:1224-9.

24. Adhya AK, Mahesha V. et al. Atypical glandular cells in cervical smears: histologicalcorrelation and a suggested plan of management based on age of the patient in a lowresource setting. Cytopathology 2009;20:375-379

25. Raab SS, Snider TE, Potts SA et al. Atypical glandular cells of undetermined significance; diagnostic accuracy and interobserver variability using select cytologic criteria. Am J Clin Pathol 1997;107:299-307

26. Ramsaroop R, Chu I. Accuracy of diagnosis of atypical glandular cells-Conventional and Thin Prep. Diagn Cytopathol 2006;34:614-9.

27. Updated Consensus Guidelines for Managing Abnormal Cervical Cancer Screening Tests and Cancer Precursors American Society for Colposcopy and Cervical Pathology Reprinted - April 2013

28. Irvin W, Evans SR, Andersen W et al. The utility of HPV DNA triage in the management of cytological AGC. Am J Obstet Gynecol 2005;193:559-65.

29. Scheiden R, Wagener C, Knolle U, Dippel W, Capesius C. Atypical glandular cells in conventional cervical smears: incidence and follow-up. BMC Cancer 2004;4:37 